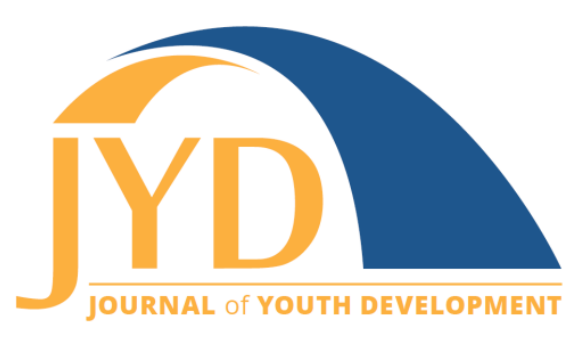

http://jyd.pitt.edu/ | Vol. 14 Issue 4 DOI 10.5195/jyd.2019.804 | ISSN 2325-4017 (online)

\title{
Promoting Youth Competence Through Balanced and Restorative Justice: A Community-Based PYD Approach
}

\author{
Rebecca Dillard \\ The Ohio State University, College of Social Work \\ dillard.113@buckeyemail.osu.edu \\ Tarkington J. Newman \\ University of New Hampshire, Department of Social Work \\ tarkington.newman@unh.edu
}

Melissa Kim

Safe Place for Youth

meliskim@gmail.com

\begin{abstract}
As responses to first-time, nonviolent juvenile offenders move towards community-based restorative justice, approaches such as the Balanced and Restorative Justice (BARJ) Model are prominent. The BARJ Model engages the youth offender, offense victim(s), and community in which the offense occurred with three associated goals: accountability, community safety, and competency development. However, while the goals of accountability and community safety are often prioritized, many community-based restorative justice programs neglect the goal of competency development, which is ultimately a disservice not only to the youth offender, but to the community. To interrupt the cyclical nature of juvenile offending and support the long-term rehabilitation of the youth offender, the integration of the BARJ model and a positive youth development (PYD) approach within the context of community-based restorative justice is proposed. PYD is grounded in the belief that all youth have the potential for healthy development, viewing them as assets and resources in community settings. To enhance long-term development, PYD objectives simultaneously promote protective factors, develop internal and external assets, and mitigate risk factors. The integration of a PYD approach within the BARJ model addresses the need to enhance youth competency development through PYD indicators inherent to many community-based programs. This article explores the conceptual compatibility of integration of the BARJ model and a PYD approach with the goal of promoting competency development among youth offenders in a restorative justice context.
\end{abstract}

Key words: positive youth development, restorative justice, youth competence, community

(c) $\mathbf{E Y}$ New articles in this journal are licensed under a Creative Commons Attribution 4.0 License. This journal is published by the University Library System, University of Pittsburgh and is cosponsored by the University of Pittsburgh Press. The Journal of Youth Development is the official peer-reviewed publication of the National Association of Extension 4-H Agents and the National AfterSchool Association. 


\section{Promoting Youth Competence}

Many communities are moving away from punitive sanctions towards a rehabilitative model of juvenile justice (Goshe, 2014), particularly for first-time, nonviolent offenders. Diversion programs, such as restorative justice, are a primary means for providing services to delinquent youth in the community while sparing them the expenses and risks of a formal court case. Though there is disagreement over a precise definition for diversion (Mears, 2012) the programs are typically aimed at intervention with first-time and/or non-violent juvenile offenders. Currently, approximately two percent of pre-adjudicated youth are diverted (Sickmund, Sladky, Kang, \& Puzzanchera, 2011). Though other populations can-and havebenefited from restorative justice interventions (Van Ness, 2005), iterations of restorative justice predominantly target first-time, non-violent offenders so as to prevent the initiation of new case files in the courts. While several models for restorative justice have been proposed and implemented in the past few decades (Van Ness, 2005), none has gained more traction in the juvenile justice system than the Balanced and Restorative Justice Model (BAR]; Pavelka, 2008; Pranis, Bazemore, Umbreit, \& Lipkin, 1998).

The BARJ model aims to balance the needs of the victim and community while promoting offender accountability (Pavelka, 2013; Pranis et al., 1998). The BARJ model engages the youth offender, offense victim(s), and community with three goals: accountability, community safety, and competency development. Facilitators of the BARJ model, however, may fail to treat these goals equally, commonly assuming that competency development is accomplished through accountability and community safety goals (Pranis et al., 1998), or failing to attribute equal weight on the basis of the ill-defined purpose, objectives, activities, and outcomes of competency development (Torbet \& Thomas, 2005). This poses a systemic challenge, as competency development is arguably the most critical for the long-term rehabilitation of the youth offender, equipping youth with skills that will empower them to be responsible, productive citizens (Pavelka, 2016). To address this lack of specific competency development and to enhance the implementation of the BARJ model, the authors propose the use of a positive youth development (PYD) approach. This manuscript explores the conceptual compatibility of integrating the BARJ model and a PYD approach with the goal of promoting competency development among youth offenders.

\section{The Need for Balanced and Restorative Justice}

According to the most recently available national report, juvenile courts handled an estimated 850,000 delinquency cases each year (Hockenberry \& Puzzanchera, 2018), many of which were 


\section{Promoting Youth Competence}

first-time offenders. The cost of incarcerating juvenile offenders is itself staggering, costing roughly $\$ 150,000$ per youth per year (Petteruti, Schindler, \& Ziedenberg, 2014); this does not include the costs of court processing, legal fees, probation expenses, or any other associated fees. Evidence suggests that contact with the juvenile justice system is not only ineffective at providing rehabilitation and decreasing offending behaviors (MacKenzie \& Farrington, 2015), but may increase the likelihood of recidivism (Henggeler \& Schoenwald, 2011). Introducing youth to a formal criminal justice system may expose them to risk for physical and sexual victimization, impeded education and job opportunities, reduced social support, and depleted mental health (Grisso, 2008; Petteruti et al., 2014; Waxman \& Collins, 2004), making them susceptible to continued offense trajectories. First-time offenders can often be successfully managed in the community without reliance on incarceration or other costly court interventions (Petteruti, Walsh, Velázquez, \& Walsh, 2009). Research has demonstrated that early intervention for youth at risk of repeated court contact has the potential to save $\$ 5.7$ million per youth over their lifetime (Cohen \& Piquero, 2009). Diversion programs, such as restorative justice, can spare not only the risks associated with formal adjudication, but also cost-effectively reduce the risk for juvenile recidivism by $8.7 \%$ (Drake, 2007).

\section{What is Restorative Justice?}

Restorative justice is a theory of justice that focuses on repairing harm caused by an offense through collaborative effort (Van Ness, 2004). Since its inception in the 1980s, restorative

justice has demonstrated itself as a non-adversarial, typically community-based alternative to formal court sanctions. The programs allow the victim, community, and offending youth to have active roles in decision-making, problem-solving, and evaluation while relieving all parties from the drawn-out process and often conflicting results of court involvement. Programs often take place within a school or community context and focus on helping the offender accept responsibility for their crime, recognize the impact of the offense on victims and the community, repair the harm caused by the offense, and leave the system with more skills than they had at entry, helping them avoid future justice system contact by becoming an engaged and productive citizen (Bergseth \& Bouffard, 2007).

\section{Balanced and Restorative Justice Model}

The BARJ model is one approach to delivering restorative justice to youth offenders. Supported by the Office of Juvenile Justice and Delinquency Prevention ([OJ]DP], 1998), BAR]'s mission is the transformation of the current juvenile justice system into a restorative approach directly 


\section{Promoting Youth Competence}

involving three primary participant groups: the youth offender, the offense victim(s), and the community in which the offense occurred. In general, restorative programming consists of interventions directly related to the offense, as the directives will be most impactful when directly related to the harm inflicted by the crime. Intervention delivery should be swift and on a consistent, truncated timeline compared to the extensive procedures of juvenile court, which can span years. Program delivery can adopt a number of formats, such as family group conferencing, community circles, peer juries, victim-offender mediation, or community reparative boards.

\section{Goals and Values of BARJ}

The goals and values of the balanced approach are elements common to all programs operating under the BARJ model. The model outlines three key goals and their associated values. The goal of accountability represents the need for the youth offender to be held responsible for their actions. The associated value is that the offending youth recognizes that they have an obligation to the victim(s) because of their actions, in addition to the community in which the offense was committed. Under this goal, youth should learn that there are consequences for behavior.

The goal of community safety is fulfilled when residents of a community feel secure and confident that they have the ability to control behavior and crime in their neighborhood. The associated value is that it is the duty of a justice system to ensure the community is safe for its members by protecting them from the juvenile offender. This goal is reached when community members are permitted to be directly involved in the crime control of their neighborhoods and active participants in determining appropriate restoration for the harm done by the youth.

Finally, the goal of competency development emphasizes helping youth identify personalized goals and strengths and assigning activities to build and capitalize on these. The ability for youth offenders to develop competence is arguably the most critical within the BARJ approach and rehabilitative processes, as it enhances their ability to develop into responsible and productive citizens within their community while mitigating their adherence to antisocial behaviors. The associated value is to equip youth offenders with the knowledge and skills that will enable them to be more capable when they leave the program than when they entered. The activities directed towards this goal should take place within the youth's community, reintegrating them as a member of the neighborhood and de-stigmatizing their presence postoffense. Thus, by promoting competency development, restorative justice can not only aid in 


\section{Promoting Youth Competence}

reducing risk for future offending and help youth to grow into law-abiding members of the community, but also mitigate the cyclical nature of juvenile offending.

\section{Outcomes of Restorative Justice}

The BARJ Model-in addition to other forms of restorative justice- has been implemented to address a range of concerns spanning crime severity, repeat offense risk, race, gender, and socioeconomic status. One study which had equitable distribution of race across restorative justice and control groups found that youth in the restorative justice group had a $40 \%$ lower likelihood of rearrests at 6-month follow-up (McGarrell, 2001). Further, the same study still found lower rearrest rates in the restorative justice group though this group contained a significantly larger number of high-risk juveniles. Juvenile participants also reported high satisfaction and appreciated that the program made them feel as though they had a say in their proceedings, compared with youth in the control group who felt they had less input in the other diversion programs (McGarrell, 2001). Another study found that female juveniles and juveniles with minimal criminal history exhibited the most benefit from restorative justice processes (Rodriquez, 2007). Results are still mixed, as other studies have demonstrated that Black juveniles and juveniles with moderate to high levels of individual and community level poverty were less likely to complete restorative justice programming, and that juveniles who lived in communities with low levels of poverty were the least likely to recidivate following restorative justice programming (De Beus \& Rodriquez, 2007).

Critical race theorists and proponents of restorative justice have both emphasized the transformative nature of restorative justice, and its capacity to help repair the harm inflicted by systemic biases that pervade the justice system (Gavrielides, 2013; Jenkins, 2006). Still, restorative justice faces the challenge of overcoming the punitive orientation of the justice system and those who work within it (Schiff, 2013). Restorative justice also cannot be separated from the sociopolitical contexts in which it operates, creating barriers for transformation to take place (Gavrielides \& Artinopoulou, 2013; Schiff 2013, Yiallourides \& Anastasiadou, 2013).

\section{Gaps in Delivery}

A considerable issue in the delivery of restorative justice programming is the allocation of priority for the three goals. While remediation is the overarching objective for restorative justice, it can only be achieved by reaching the three corresponding goals. Providing restitution 


\section{Promoting Youth Competence}

for victims and addressing the concerns of community members around safety, while serious, should not be granted more weight than competency development for the youth offender (Maloney, Romig, \& Armstrong, 1998). However, BARJ has been criticized for attempting to rebrand traditional retributive justice practices under the guise of adopting a restorative paradigm (Bazemore \& Schiff, 2001). When youth competency is underemphasized in deference to the goals of accountability and community safety, the primary preventative componentstransferable skill development and reduced social isolation-are sacrificed. This is dangerous because the BARJ Model is federally sanctioned and funded by the Office of Juvenile Justice and Delinquency Prevention, despite its treatment of competency development as an augmented add-on to the favored victim and community justice components rather than an equally weighted and essential ingredient (McCold, 2004).

Insufficient guidance around the implications of youth competence for recidivism prevention and how to deliver activities supporting youth development within a justice-based program may partially explain the concern around goal discrepancy. Providing practical and concrete guidelines on how to create or partner with existing programming for youth competence may be a necessity, especially considering that interventions are typically delivered by community members as opposed to trained social work interventionists with experience in the field of juvenile justice.

\section{A Positive Youth Development Approach}

Derived from ecological and developmental systems theories (Catalano, Berglund, Ryan, Lonczak, \& Hawkins, 2004; Lerner, 2002), PYD asserts that interactions between social systems affect one's development. PYD is grounded in a strengths-based perspective that all youth have the potential for successful, healthy development.

\section{PYD Program Features}

While PYD-based programming and practices have been utilized in a variety of contexts (e.g., afterschool programs, summer sport camps, residential treatment facilities), researchers have begun to identify key program features inherent to effective programming. Arguably, the most recognized features were provided by Eccles and Gootman (2002). Specifically, communitybased PYD programs should provide: 


\section{Promoting Youth Competence}

- physical and psychological safety where youth feel safe to take risks and share their thoughts and feelings;

- appropriate structure though developmentally appropriate rules and expectations;

- positive social norms by creating agreed upon behavioral expectations and a shared value system;

- support for efficacy and mattering by being youth-centric, providing autonomy support and empowering youth;

- supportive relationships between both staff and peers by practicing effective communication and demonstrating care for youth;

- opportunities to belong through meaningful inclusionary tactics and strategies that promote social engagement;

- opportunities for skill building that match the desired outcomes of the program; and

- integration of efforts throughout the community by coordinating synergetic energies.

Additionally, in review of recent literature, the authors of the current article propose two additional program features: trained adult leaders and culturally competent programming. Community-based PYD programs rely on trained adult leaders to implement programming, develop positive relationships with youth, and facilitate positive developmental outcomes (Jones \& Deutsch, 2011; Zeldin, Christens, \& Powers, 2013). For instance, Newman, AndersonButcher, and Amorose (2018) demonstrated that in a community-based PYD program, supportive practices by staff predicted life skill, social competence, and transfer of learning outcomes. Culturally competent programming also is a critical component (Fraser-Thomas, Côté, \& Deakin, 2005; Jackson, 2009), as the adult leaders do not often culturally represent the youth they are serving. This cultural mismatch can result in programs and staff who have a limited awareness of and/or insensitivity to specific cultural issues (Castro, Barrera, \& Martinez, 2004). Therefore, the capacity to develop culturally competent programming that is facilitated by trained adult leaders is an important program feature to meet the needs of youth.

\section{PYD Outcome Indicators}

Researchers have developed a standard vocabulary to discuss PYD outcome indicators, known as the 6 C's. These indicators include: competence, confidence, connection, character, caring, and contribution (Lerner et al., 2005). Competence is one's positive views of one's actions in the different areas of life including social, academic, cognitive, health, and vocational contexts. Confidence refers to feeling overall positive self-worth and self-efficacy. Connection refers to positive bonds between people and institutions, in which both parties meaningfully contribute to 


\section{Promoting Youth Competence}

the relationship. Character holds that one respects societal and cultural norms and exhibits prosocial behaviors. Caring is used to mean that one demonstrates a sense of sympathy and empathy for others and their circumstances. Finally, when youth embody the first $5 C^{\prime}$ 's, they have the potential to develop the sixth $\mathrm{C}$, contribution. Contribution indicates one's contributions to self, family, community, and institutions of a civil society.

\section{Promoting Competency Development}

The combination of risk reduction and promoting protection through PYD has been recommended as a viable approach when working with youth (Catalano, Hawkins, Berglund, Pollard, \& Arthur, 2002; Riestenberg, 2008). Further, several other advocates have, at least in part, proposed the utility of the combination of PYD principles and restorative justice programming and practices. For example, the National Juvenile Justice Network (2010) proposed that juvenile justice be implemented with a focus on PYD. Specifically, juvenile justice programs should adopt a PYD perspective and other strength-based strategies, rather than viewing youth from a deficit perspective and focusing on their "problems." Similarly, Butts, Bazemore, and Meroe (2010) posited, "the concepts and principles of [PYD] offer valuable guidance for the design of interventions for youthful offenders" (p. 7). Liddell, Clark, and Starkovich (2014) contested that while PYD programming does not require a specific set of curricula, the activities and experiences for youth should be planned and intentional. Ultimately, Schwartz (2017) forwarded, "Principles of adolescent development have accelerated positive changes to the juvenile justice system. These changes have been most pronounced in reducing reliance on incarceration and in approaches to sentencing of youth tried as adults" (p. 2).

A variety of programs have recognized the benefit of using restorative practices to aid in positive youth development. The conceptual alignment of PYD and restorative justice was enumerated in addressing school bullying, advocating for use of restorative practices not only to address the concerns for both bully and victim, but also to foster healthy development for involved youth (Riestenberg, 2008). Maine's Juvenile Justice Advisory Group has been advised in a report to seek to instill restorative practice at all levels of public youth-serving systems as a means of fostering healthy youth development (Burford et al., 2016). Youth courts in Massachusetts have also seen high rates of compliance and low rates of recidivism in their programs, which are embedded in the principles of restorative justice and aim to aid in the development of life skills and positive relationships (New Bedford Youth Court History and Summary, 2016). 


\section{Promoting Youth Competence}

However, while other advocates have proposed the utility of PYD within a spectrum of restorative justice programming and practices, many of the previous efforts have not specified or provided explicit frameworks. This gap is particularly prevalent related to PYD and BARJ programming and practices. More specifically, Schwartz (2016) contested, "Unfortunately, most of the early state efforts to re-align their juvenile justice systems with a BARJ philosophy have fallen short. It was easiest for states to begin by focusing on public safety and accountability rather than by figuring out the meaning of competency development" (p. 266). Therefore, further work must be done to more effectively integrate PYD and restorative justice initiatives.

Thus, the authors of this article seek to present an integrated framework to fulfill the need for a more structured delivery to promote youth competency development (see Figure 1). The PYDInformed Restorative Justice Framework to Promote Competency Development is grounded in the seminal work of Eccles and Gootman (2002) as well as additional advances in the field of community-based PYD programming related to trained adult leaders and culturally competent programming. To illustrate the framework, particularly the integration of the BARJ model and a PYD approach, descriptions of each component of the framework are provided. Additionally, to emphasize this new framework's commitment to advancing youth competency development, related PYD outcome indicators as identified by Lerner and colleagues (2005) are highlighted and examples are provided for how the indicators would be visible in a BARJ setting (see Table 1). 
Promoting Youth Competence

Figure 1. A PYD-Informed Restorative Justice Framework to Promote Competency Development

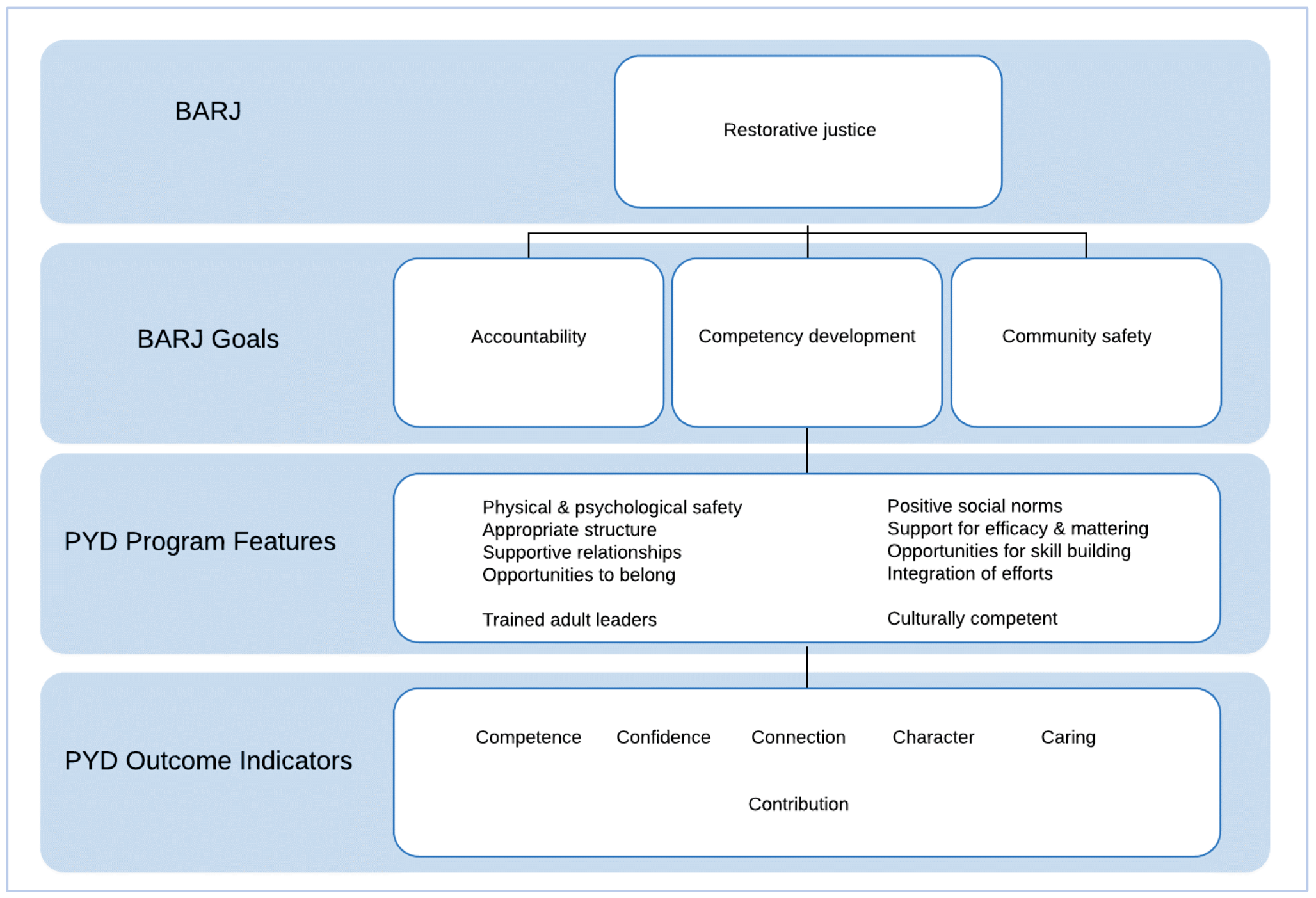


Table 1. PYD Outcome Indicators Within a PYD-Informed Restorative Justice Framework to Promote Competency Development

\begin{tabular}{|c|c|c|}
\hline $\begin{array}{l}\text { PYD outcome } \\
\text { indicators }\end{array}$ & $\begin{array}{l}\text { Definition of PYD outcome } \\
\text { indicator }\end{array}$ & $\begin{array}{l}\text { Examples within restorative justice } \\
\text { programs }\end{array}$ \\
\hline Competence & $\begin{array}{l}\text { Believing in one's knowledge, } \\
\text { skills, and abilities. }\end{array}$ & $\begin{array}{l}\text { Youth participants develop transferrable } \\
\text { knowledge, skills, and abilities that can be } \\
\text { used across different settings and help them } \\
\text { become active, contributing members of their } \\
\text { communities. }\end{array}$ \\
\hline Confidence & $\begin{array}{l}\text { Maintaining a sense of positive } \\
\text { self-worth and self-efficacy. }\end{array}$ & $\begin{array}{l}\text { Youth participants view themselves complexly } \\
\text { as autonomous individuals, gaining a sense of } \\
\text { control over their decisions and leave the } \\
\text { program free of any stigma associated with } \\
\text { their transgression. }\end{array}$ \\
\hline Connection & $\begin{array}{l}\text { Developing positive } \\
\text { relationships with other people } \\
\text { and institutions. }\end{array}$ & $\begin{array}{l}\text { Youth participants build connections with } \\
\text { community members, prosocial peers, and } \\
\text { organizations supportive of their competency } \\
\text { development that they can maintain once they } \\
\text { complete the program. }\end{array}$ \\
\hline Character & $\begin{array}{l}\text { Adhering to prosocial cultural } \\
\text { and societal norms and values. }\end{array}$ & $\begin{array}{l}\text { Youth participants commit to achieving the } \\
\text { goals they have set out for themselves and } \\
\text { commit to not having future contact with the } \\
\text { juvenile justice system. }\end{array}$ \\
\hline Caring & $\begin{array}{l}\text { Having a sense of sympathy } \\
\text { and empathy for others. }\end{array}$ & $\begin{array}{l}\text { Youth participants recognize and acknowledge } \\
\text { the negative impact their offense had on } \\
\text { themselves, their families, the victim, and the } \\
\text { broader community, and have worked to repair } \\
\text { the harm. }\end{array}$ \\
\hline Contribution & $\begin{array}{l}\text { Contributing to self, family, } \\
\text { community, and society. }\end{array}$ & $\begin{array}{l}\text { Youth participants see themselves as capable } \\
\text { individuals with agency to achieve their goals } \\
\text { and be active, contributing members of their } \\
\text { communities. }\end{array}$ \\
\hline
\end{tabular}




\section{Promoting Youth Competence}

\section{Physical and Psychological Safety}

Safety is a prerequisite to any community-based PYD program that aims to promote youth competence. As safety is both a physical and psychological phenomenon, programs should be conducted in environments that are both physically and psychologically safe. Physically safe programs should occur in locations free of hazardous materials and unsafe health conditions. Psychologically safe programs must be in locations that are free of environmental stressors, such as the fear of danger. For instance, program settings should be in neighborhoods that are not associated with antisocial behaviors. Furthermore, programs should be housed in an environment where youth have the opportunity to discuss their perspectives and lived experience, free of prejudice.

In a restorative justice context, the program environment should not only be psychologically safe, but conducive to the development of confidence whereby the youth can engage in nonjudgmental exploration. Program meetings should occur in the youth offender's own community in a semi-private venue outside of the building housing juvenile court. If possible, the location should be central within the community and publicly accessible while affording enough privacy to protect all participating parties from scrutiny. Potential spaces to utilize include recreational centers, places of worship, libraries, school buildings, and other community resource centers.

\section{Positive Social Norms}

Successful community-based PYD programs develop prosocial cultural norms which are shared by all youth and adult staff. Positive social norms refer to the values, morals, and ethics that a program wishes to instill. These ideals operate as unwritten rules and comprise the overall culture of a program, grounding program design and providing a backbone for program practices.

To meet this feature's requirements, restorative justice programs should develop parameters, guidelines, and rules that promote the development of prosocial character traits. Any positive social norms should be inclusively shared by the youth offender, family of the youth, community members, court supervisor, and victim and victim supports (if appropriate), and should set a tone of honesty and respectful conduct. Additionally, programs should establish common goals amongst participants and champion an environment of active participation and collaboration. Preventing the emergence of combative attitudes and instilling a mentality of all participants being on the same team can contribute to the adoption of positive social norms within the group dynamic. 


\section{Promoting Youth Competence}

\section{Appropriate Structure}

Community-based PYD programs should be structured to meet the developmental needs of youth. This means that they are age appropriate and designed to fit the biopsychosocial capacities of youth. Appropriate structure also means that programs operate with clear, enforced rules and expectations. Setting boundaries and supplying a consistent structure that provides guidelines for youth should be balanced with the offer of autonomy support which is imperative to youth development. Effective programs offer a sense of continuity and predictability, while limiting stressors which could lead to a chaotic and unproductive environment.

Restorative justice emphasizes developmental responsiveness to the needs of youth offenders, thereby enhancing their competence and confidence in themselves and their abilities. Program materials, rules, and assignments must be developmentally appropriate. Rules should be clear, repeated, and displayed prominently throughout the program. Further, rules surrounding conduct, respect, and communication should be reinforced by facilitators of the program. Any assignments that will take place outside of the direct restorative justice location should be explored and confirmed to have appropriate levels of structure and supervision. Program guidelines should be presented to youth as mirroring the laws and rules that govern social interaction and community participation, providing an opportunity to successfully operate with autonomy in an environment with structure, consequences, and expectations. Youth should also be granted decision making autonomy to determine which skills they would like to develop and programs that appeal to their needs, so long as clear rules, expectations, and other structural components are elucidated.

\section{Supportive Relationships}

Effective community-based PYD programs also promote the creation and maintenance of supportive interpersonal relationships. These relationships are often fostered between multiple youth, as well as between youth and adult staff. Although there is no single template for supportive relationships, they are often characterized by connectedness, responsiveness, caring, and effective communication. By cultivating supportive relationships, youth have the opportunity to develop secure attachments with prosocial peers and adult role models. 


\section{Promoting Youth Competence}

As traditional juvenile justice systems tend to be comprised of adversarial relationships, supportive relationships should be a focal point of restorative justice programming. Program facilitators should be trained to mediate communication between youth offenders and the victim, youth offenders and the court, youth offenders and their family, as well as youth offenders and their community. Additionally, facilitators must continually ensure that youth feel that they can trust and confide in them without being misrepresented or betrayed. Supportive relationships can help facilitators encourage youth in their competency development and reinforce the belief that youth are capable of learning and growing from their missteps. Effective relational support also may help all participants in the restorative justice process-such as court representatives, victims, parents, and the juveniles themselves-to view youth in this same positive regard. The maintenance of these supportive connections can ease community reintegration for the youth and their family by neutralizing risk of stigma and isolation.

\section{Opportunities to Belong}

Similar to the importance of developing supportive relationships is the opportunity to internalize a sense of belonging amongst peers, adult staff, as well as the program. Community-based PYD programs should be designed to promote an inclusive environment, regardless of gender, race/ethnicity, gender identity and sexual orientation, and/or ability. By building programmatic social norms that embrace social inclusion and engagement, programs strengthen a sense of acceptance between peers and adult staff, as well as attachment to the program.

Belonging is particularly important for youth offenders who have been in contact with the juvenile justice system. Restorative justice not only allows youth to remain in the community physically, but can capitalize on the opportunity to reduce the ostracism and stigma associated with criminal adjudication by helping youth actively and visibly engage in the community. Thus, meetings and assigned activities should all take place within the youth's community, allowing youth to develop meaningful connections with individuals and institutions. Additionally, joint investment and acceptance can help youth, their parents, the victim(s), and the community members all feel connected to the mission of restorative justice as a whole. The caring expressed through interpersonal exchanges can allow a symbiotic relationship between the youth and the community to develop. 


\section{Promoting Youth Competence}

\section{Support for Efficacy and Mattering}

At the heart of community-based PYD programs is providing support for efficacy and mattering of all youth. These programs are youth-centered and empower youth to make meaningful decisions, thus supporting their autonomy. By providing opportunities to make decisions that impact their own development, youth take responsibility for their behaviors and actions. Moreover, support for efficacy and mattering focuses on individual development and competence rather than comparative assessments and performance-based evaluations.

In restorative justice, satisfying needs for efficacy and mattering are all the more poignant for youth offenders who have been labeled by a justice system and community as "bad kids," delinquents, or criminals, which can be damaging to their self-image. Facilitators should be patient with youth as they process their thoughts and emotions, encourage youth selfexpression and creativity, and be flexible to allow youth to meet program requirements in ways that acknowledge and enhance their individual strengths, building the competence of youth and confidence in their abilities. Through carrying out the sentencing plan of the restorative program, youth should come to realize that they have the ability to make an impact, either positive or negative, and that their choices and behavior matter for themselves, their family, and the community. Assignments should be focused on youth moving forward rather than dwelling on and/or rehashing the troublesome behavior that led to their program entry.

\section{Opportunities for Skill Building}

One of the main priorities for community-based PYD programs is the aim of promoting the development of transferable values, skills, and competencies. With this aim, programs must supply ample opportunities for youth to practice and apply newly learned skills within the learning context (i.e., the program). Further, effective programs provide youth opportunities to then practice the newly acquired skills outside of the program. When youth practice new skills and apply them in different contexts, they are better equipped to transfer skills they have learned.

Restorative justice programs should not only promote the development of knowledge and skills that will help youth offenders achieve their goals, but should be designed to promote competence with their newly acquired knowledge and skills. Skills to be enhanced should be self-identified by the youth (e.g., skills for academic success) as well as skills that will mitigate future contact with the juvenile justice system (e.g., problem-solving and decision-making skills). Facilitators are tasked with working in tandem with youth, their families, and victim(s) to 


\section{Promoting Youth Competence}

assign achievable and measurable skill development opportunities. Additionally, assignments to promote skill building should challenge the youth to practice newly acquired skills in a variety of contexts. Mastery experiences with new skills should be provided to give youth the opportunity to not only practice, but succeed in applying that skill across situations, building confidence in their ability to transfer learning to various life domains.

\section{Integration of Efforts}

To address the biopsychosocial development of youth, many community-based PYD programs offer holistic programming. Effective programs should engage external assets and key social resources such as the family, school, and community. By coordinating with other key external assets and social resources, programs can offer wraparound services to better ensure the diverse needs of youth are supported throughout the community.

Restorative programs should be carried out in collaboration with the offending youth, their family, the victim(s) and victim supports (if appropriate), members of the community, and the juvenile court. Other settings that can contribute to positive development should also be integrated when and where able (e.g., school, extracurricular activities, faith-based organizations, etc.). Individuals in each setting are stakeholders in promoting the development of prosocial character of youth. As a restorative justice program for youth becomes a prominent community presence, an ongoing list of available community supports, services, and resources should be compiled. Reciprocal relationships can be established whereby youth benefit from the community resource while becoming a source of positive contribution to the community.

\section{Trained Adult Leaders}

Youth are susceptible to environmental risk factors and stressors and can be influenced by key adult figures. Therefore, effective community-based PYD programs should be implemented by adult leaders-primarily leaders and key stakeholders from the local community-who are trained in the program's theory of change and educated in youth development. Often these community members are actively engaged in other community initiatives and efforts; and therefore, these adult leaders are suited to represent both the community, as well as the best interest of the youth whom they are working with. These trained adult leaders should promote prosocial norms, develop meaningful relationships with youth, and actively facilitate experiences within the program towards the desired values, skills, and competencies. Moreover, trained adult leaders should partner with youth to help process and debrief experiences, bringing 


\section{Promoting Youth Competence}

transcendent meaning to their participation. Further, by partnering with members of the community-who are not inherently associated with the justice system-youth may develop a sense of belonging to both the community member as well as the community as a whole.

As restorative justice programs are often implemented and facilitated by volunteer community members, these adult leaders must be trained. For instance, facilitators should be mandated to receive training in restorative justice practices and PYD approaches under the supervision of a court representative or director. Training should include skill development, highlighting the benefits and importance of mediation and debriefing, active listening, and empathy. Facilitators also must be advocates for parties that feel underrepresented, particularly if the offending youth feels their needs and/or concerns are not being seriously considered in the restorative justice process. If possible, it can be advantageous if facilitators are visible members of the youth's community to provide continuous reinforcement of each of the PYD outcome indicators (i.e., competence, confidence, connection, character, caring, and contribution), even after the extent of their program involvement has concluded.

\section{Cultural Competence}

Youth development occurs within layers of the environment which are influenced by many socio-political factors. For instance, family history, cultural norms, and societal expectations influence the lived experiences and worldview of youth offenders. Because community-based PYD programs operate within unique neighborhoods and communities, programs must be aware of the cultural context and integrate key cultural components of its participants throughout its programming. By being respectful and responsive to ever-evolving, dynamic cultures, programs are better able to honor diversity while promoting inclusiveness throughout the program.

Restorative justice must account for not only the family, neighborhood, and socio-political contexts of youth offenders, but also dynamics of crime-supportive cultural attitudes and worldviews. Crime-supportive culture must be acknowledged, not disparaged, as a number of events, experiences, and risk factors may have contributed to youth assigning significance to a culture that rewards delinquency. Programs should integrate key cultural components by hosting programs within the youth's community, having community members facilitate the program, and taking into consideration the community's social norms. By offering culturally competent programming, youth not only develop through the restorative justice process, but proceed to provide meaningful contributions to the community's understanding of crime- 


\section{Promoting Youth Competence}

supportive cultures which may have ultimately influenced the youth's mistakes and undesirable behaviors. To this end, culture must be infused into programming and assignments to make skill development realistic and practical for the youth's continued membership in a culturally complex setting.

\section{Conclusion}

As society moves away from punitive sanctions and towards a socially just, rehabilitative model when working with first-time, nonviolent youth offenders, approaches such as the BARJ model are becoming more frequently utilized. With the goal of promoting competency development, this article explored the conceptual compatibility of integration of the BARJ model and a PYD approach to program delivery. Through this PYD-informed restorative justice framework, specific program features and their application within a community-based restorative justice context are offered. Practitioners in juvenile justice settings and in youth-serving community organizations can benefit from this framework by pursuing collaborative partnerships to effectively and positively intervene with youth offenders to redirect their trajectories towards community engagement and away from continued offending. The proposed framework can also guide the implementation of positive youth development features to serve the BARJ goal of competency development for offending youth through providing clear outcomes and activities to support restorative efforts. More effective restorative justice programs for first-time, nonviolent youth offenders may not only mitigate the risk for perpetual offenses, but also enhance the positive long-term development of youth.

\section{References}

Bazemore, G., \& Schiff, M. (2001). Understanding restorative community justice: What and why now? In G. Bazemore \& M. Schiff (Eds.), Restorative community justice: Repairing harm and transforming communities (pp. 21-46). Cincinnati, $\mathrm{OH}$ : Anderson.

Bergseth, K. \& Bouffard, J. (2007). The long-term impact of restorative justice programming for juvenile offenders. Journal of Criminal Justice, 35(4), 433-451. doi:10.1016/j.jcrimjus.2007.05.006

Burford, G., Wheeldon, J., Gallagher, S., Gennette, K., Gorczyk, J., \& Shaler, G. (2016, October). An initiative to develop a sustainable restorative juvenile justice system blueprint for a restorative state: Work plan and recommendations presented to Maine's juvenile justice advisory group. Retrieved from http://www.maine.gov/corrections/jjag/publications/JJAG\%20BluePrint.PDF 
Promoting Youth Competence

Butts, J., Bazemore, G., \& Meroe, A. (2010). Positive youth justice: Framing justice interventions using the concepts of positive youth development. Washington, DC: Coalition for Juvenile Justice.

Castro, F., Barrera, M., \& Martinez, C. (2004). The cultural adaptation of prevention interventions:

Resolving tensions between fidelity and fit. Prevention Science, 5(1), 41-45.

doi:10.1023/B:PREV.0000013980.12412.cd

Catalano, R., Berglund, M., Ryan, J., Lonczak, H., \& Hawkins, J. (2004). Positive youth development in the United States: Research findings on evaluations of positive youth development programs. Annals of the American Academy of Political and Social Science, 591(1), 98-124. doi:10.1037//1522-3736.5.1.515a

Catalano, R., Hawkins, J., Berglund, M., Pollard, J., \& Arthur, M. (2002). Prevention science and positive youth development: Competitive or cooperative frameworks?. Journal of Adolescent Health, 31(6), 230-239. doi:10.1016/s1054-139x(02)00496-2

Cohen, M., \& Piquero, A. (2009). New evidence on the monetary value of saving a high risk youth. Journal of Quantitative Criminology, 25(1), 25-49. doi:10.1007/s10940-008-9057-3

De Beus, K., \& Rodriguez, N. (2007). Restorative justice practice: An examination of program completion and recidivism. Journal of Criminal Justice, 35(3), 337-347. doi:10.1016/j.jcrimjus.2007.03.009

Drake, E. (2007). Evidence-based juvenile offender programs: Program description, quality assurance, and cost. Olympia: Washington State Institute for Public Policy, Document No.07-06-1201. Retrieved from http://www.wsipp.wa.gov/ReportFile/986/Wsipp_Evidence-Based-JuvenileOffender-Programs-Program-Description-Quality-Assurance-and-Cost_Full-Report.pdf

Eccles, J., \& Gootman, J. (Eds.). (2002). Community programs to promote youth development. Washington, DC: National Academy Press.

Fraser-Thomas, J., Côté, J., \& Deakin, J. (2005). Youth sport programs: An avenue to foster positive youth development. Physical Education \& Sport Pedagogy, 10(1), 19-40. doi: $10.1080=1740898042000334890$

Gavrielides, T. (2013). Restorative pain: A new vision of punishment. In T. Gavrielides \& V. Artinopoulou (Eds.), Reconstructing restorative justice philosophy (pp. 311-337). Furnham, UK: Ashgate.

Gavrielides, T., \& Artinopoulou, V. (2013). Reconstructing restorative justice philosophy. Furnham, UK: Ashgate.

Goshe, S. (2015). Moving beyond the punitive legacy: Taking stock of persistent problems in juvenile justice. Youth Justice, 15(1), 42-56. doi:10.1177/1473225414537930

Grisso, T. (2008). Adolescent offenders with mental disorders. The future of children, 18(2), 143-164. Henggeler, S., \& Schoenwald, S. (2011). Social policy report: Evidence-based interventions for juvenile offenders and juvenile justice policies that support them. Society for Research in Child Development 25(1), 1-28. doi:10.1002/j.2379-3988.2011.tb00066.x 
Promoting Youth Competence

Hockenberry, S., \& Puzzanchera, C. (2018). Juvenile court statistics 2016. Pittsburgh, PA: National Center for Juvenile Justice. Retrieved from http://www.ncjj.org/pdf/jcsreports/jcs2016report.pdf

Jackson, K. (2009). Building cultural competence: A systematic evaluation of the effectiveness of culturally sensitive interventions with ethnic minority youth. Children and Youth Services Review, 31(11), 1192-1198. doi:10.1016/j.childyouth.2009.08.001

Jenkins, M. (2006). Gullah Island dispute resolution: An example of Afrocentric restorative justice. Journal of Black Studies, 372), 299-319. Retrieved from http://www.jstor.org/stable/40034415

Jones, J., \& Deutsch, N. (2011). Relational strategies in after-school settings: How staff-youth relationships support positive development. Youth \& Society, 43(4), 1381-1406. doi:10.1177/0044118X10386077

Lerner, R. (2002). Concepts and theories of human development ( $3^{\text {rd }}$ ed.). Mahwah, NJ: Lawrence Erlbaum.

Lerner, R., Lerner, J., Almerigi, J., Theokas, C., Phelps, E., Gestsdottir, S., . . von Eye, A. (2005). Positive youth development, participation in community youth development programs, and community contributions of fifth grade adolescents: Findings from the first wave of the 4-H Study of Positive Youth Development. Journal of Early Adolescence, 25(1), 17-71. doi:10.1177/0272431604272461

Liddell, W., Clark, P., \& Starkovich, K. (2014). Effective programs and services. In Desktop guide to quality practice for working with youth in confinement. National Partnership for Juvenile Services and Office of Juvenile Justice and Delinquency Prevention. Retrieved from: https://info.nicic.gov/dtg/node/16\#_edn2

MacKenzie, D., \& Farrington, D. (2015). Preventing future offending of delinquents and offenders: what have we learned from experiments and meta-analyses?. Journal of Experimental Criminology, 11(4), 565-595.

Maloney, D., Romig, D., \& Armstrong, T. (1998). Juvenile probation: The balanced approach. Juvenile and Family Court Journal, 39(3). doi:10.1111/j.1755-6988.1988.tb00623.x

McCold, P. (2004). Paradigm muddle: The threat to restorative justice posed by its merger with community justice. Contemporary Justice Review, 71 ), 13-35. doi:10.1080/1028258042000211987

McGarrell, E. (2001). Restorative justice conferences as an early response to young offenders. Washington, DC: U.S. Department of Justice, Office of Justice Programs, Office of Juvenile Justice and Delinquency Prevention. Retrieved from National Criminal Justice Reference Service website: https://www.ncjrs.gov/pdffiles1/ojjdp/187769.pdf

Mears, D.P. (2012). The front end of juvenile court: Intake and informal versus formal processing. In B. Feld and D. Bishop (Eds.), The Oxford handbook of juvenile crime and juvenile justice (pp. 573605). New York, NY: Oxford University Press. 


\section{Promoting Youth Competence}

National Juvenile Justice Network. (2010). Approaching juvenile justice with a focus on positive youth development. Retrieved from: http://www.njjn.org/uploads/digital-library/resource_1427.pdf

New Bedford Youth Court History and Summary (2016). Retrieved from https://www.newbedfordguide.com/new-bedford-youth-court-history-and-summary.

Newman, T., Anderson-Butcher, D., \& Amorose, A. (2018). Examining the influence of sport program staff and parent/caregiver support on youth outcomes. Applied Developmental Science. doi:10.1080/10888691.2018.1467762

Pavelka, S. (2008). Restorative juvenile justice legislation and policy: A national assessment. International Journal of Restorative Justice, 4(2): 100-118. Retrieved from http://www.justicereparatrice.org/www.restorativejustice.org/legislative-assembly/15statutescases-regulations-and-recommendations-from-national-regional-and-intergovernmentalbodies/restorative-justice-and-the-law/statutes/restorative-juvenile-justice-legislation-and-policya-national-assessement

Pavelka, S. (2013). Practices and policies for implementing restorative justice within schools. The Prevention Researcher, 20(1), 15-18.

Pavelka, S. (2016). Restorative justice in the states: An analysis of statutory legislation and policy. Justice Policy Journal, 13(2), 1-23. Retrieved from https://www.nacrj.org/images/pdf/Restorative_ Justice_in_the_States-An_Analysis_of_Statutory_Legislation_and_Policy_2.pdf

Petteruti, A., Schindler, M., \& Ziedenberg, J. (2014). Stickershock: Calculating the full price tag for youth incarceration. . Retrieved from Justice Policy Institute website: http://www.justicepolicy.org/ uploads/justicepolicy/documents/sticker_shock_final_v2.pdf

Petteruti, A., Walsh, N., \& Velázquez, T. (2009). The costs of confinement: Why good juvenile justice policies make good fiscal sense. Retrieved from Justice Policy Institute website: http://www.justicepolicy.org/images/upload/09_05_rep_costsofconfinement_jj_ps.pdf

Pranis, K., Bazemore, G., Umbreit, M., \& Lipkin, R. (1998). Guide for implementing the balanced and restorative justice model. Retrieved from Office of Juvenile Justice and Delinquency Prevention website: https://www.ojjdp.gov/pubs/implementing/ack.html.

Riestenberg, N. (2008). Applying the framework: Positive youth development and restorative practices. Journal of Youth Development, 3(1), 113-122. doi:10.5195/jyd.2008.324

Rodriguez, N. (2007). Restorative justice at work: Examining the impact of restorative justice resolutions on juvenile recidivism. Crime \& Delinquency, 53(3), 355-379. doi:10.1177/0011128705285983

Sickmund, M., Sladky, A., Kang, W., \& Puzzanchera, C. (2011). Easy access to the census of juveniles in residential placement. Retrieved from Office of Juvenile Justice and Delinquency Prevention website: www.ojjdp.gov/ojstatbb/ezacjrp/ 


\section{Promoting Youth Competence}

Schiff, M. (2013). Institutionalizing restorative justice: Paradoxes of power, restoration, and rights. In T. Gavrielides \& V. Artinopoulou (Eds.), Reconstructing restorative justice philosophy (pp. 153-179). Furnham, UK: Ashgate.

Schwartz, R. (2016). Juvenile justice and positive youth development. In R. Schwartz (Ed.). Youth development: Issues, challenges, and directions. Philadelphia, PA: Public/Private Ventures.

Schwartz, R. (2017). Youth on probation: Bringing a $20^{\text {th }}$ century service into a developmentally friendly $21^{\text {st }}$ century world. Philadelphia, PA: Stoneleigh Foundation.

Torbet, P. \& Thomas, D. (2005). Advancing competency development: A white paper for Pennsy/vania. Pittsburgh, PA: National Center for Juvenile Justice. Retrieved from https://www.pccd.pa.gov/ Juvenile-Justice/Documents/whitepapers.pdf

Van Ness, D. (2004, August). RJ City\&: Contemplating a restorative justice system. Paper presented at the International Institute for Restorative Practices conference, Vancouver, Canada.

Van Ness, D. (2005, April). An overview of restorative justice around the world. Paper presented at the Eleventh United Nations Congress on Crime Prevention and Criminal Justice, Bangkok, Thailand.

Waxman, H., \& Collins, S. (2004). Incarceration of youth who are waiting for community mental health services in the United States. U.S. House of Representatives, Committee on Government Reform. Retrieved from https://www.hsgac.senate.gov/imo/media/doc/040707juvenilereport.pdf

Yiallourides, C., Anastasiadou, M. (2013). Global justice, restorative justice and universal peace in the reality of international politics and state power. In T. Gavrielides \& V. Artinopoulou (Eds.), Reconstructing restorative justice philosophy (pp. 131-153). Furnham, UK: Ashgate.

Zeldin, S., Christens, B., \& Powers, J. (2013). The psychology and practice of youth-adult partnership: Bridging generations for youth development and community change. American Journal of Community Psychology, 51(3-4), 385-397. doi:10.1007/s10464-012-9558-y 